\title{
Robotic transoral thyroidectomy for papillary thyroid carcinoma
}

\author{
Hong Kyu Kim ${ }^{1, *}$, Dawon Park ${ }^{2, *}$, Hoon Yub Kim² \\ ${ }^{1}$ Department of Surgery, Seoul National University College of Medicine, Seoul, Korea \\ ${ }^{2}$ Department of Surgery, KUMC Thyroid Center, Korea University Hospital, Korea University College of Medicine, Seoul, Korea
}

\begin{abstract}
Transoral robotic thyroidectomy (TORT) is well consistent with the primary goal of remote-access thyroid surgery, which is to avoid a visible cervical scar. Additionally, the extent of transoral thyroidectomy dissection is less than that of other remote-access surgical procedures. Owing to these merits of the transoral approach, several institutions around the world are now performing this procedure. Since transoral thyroidectomy is performed in a confined, narrow space, and is characterized by a close distance from the ports to the working space, more benefits can be derived from multiarticulation of robotic instruments. Especially when performing left lobectomy by TORT, the surgeon can use right-handed robotic instruments over the thyroid cartilage with the merits of multiarticulation. In this study, we present our unique procedure of left lobectomy by TORT in detail.
\end{abstract}

[Ann Surg Treat Res 2019;96(5):266-268]

Key Words: Transoral thyroidectomy, Remote-access thyroidectomy, Transoral robotic thyroidectomy

\section{INTRODUCTION}

Among the various remote-access approaches for thyroid surgery, the transoral approach is recently drawing attention because it requires minimal flap dissection and provides excellent cosmetic outcomes [1-3]. Recently, we've successfully introduced a robotic surgical system to the transoral approach and reported the feasibility of transoral robotic thyroidectomy (TORT) [4-6].

Technical differences exist between right and left thyroid lobectomy in the transoral robotic approach. The most notable difference of left lobectomy compared with right lobectomy by the transoral robotic approach is that the main acting arm changes from right to left. Most surgeons use a right-handed instrument to perform the main procedure while using lefthanded instruments for traction of the tissue. In left lobectomy by transoral robotic approach, however, the surgeon should perform the main procedure with left-handed instruments because it is difficult to use right-handed instruments over the thyroid cartilage. This can be a major obstacle for beginners to perform left lobectomy by transoral approach.

In this study, we present our unique procedure of transoral robotic left lobectomy in detail.

\section{SURGICALTECHNIQUE}

\section{Patient}

This study was approved by the Institutional Review Board of Korea University Hospital (approval number: 2017AN0077). A 35-year-old female patient with a BMI of $21.33 \mathrm{~kg} / \mathrm{m}^{2}$ was found to have a $0.9-\mathrm{cm}$-sized nodule in her left thyroid lobe on ultrasound. Fine needle aspiration biopsy showed papillary
Received November 27, 2018, Reviewed December 27, 2018,

Accepted January 14, 2019

\section{Corresponding Author: Hoon Yub Kim}

Department of Surgery, Korea University College of Medicine, 73 Inchonro, Seongbuk-gu, Seoul 02841, Korea

Tel: +82-2-920-6849, Fax: +82-2-928-1631

E-mail: hoonyubkim@gmail.com

ORCID code: https://orcid.org/0000-0002-6731-3912
*Hong Kyu Kim and Dawon Park contributed equally to this study as cofirst authors.

Copyright (C) 2019, the Korean Surgical Society

(c) Annals of Surgical Treatment and Research is an Open Access Journal. All articles are distributed under the terms of the Creative Commons Attribution NonCommercial License (http://creativecommons.org/licenses/by-nc/4.0/) which permits unrestricted non-commercial use, distribution, and reproduction in any medium, provided the original work is properly cited. 
carcinoma (Bethesda category VI). Since the patient did not want to have a surgical scar on her neck, after counseling on the various approaches for thyroid surgery, she underwent TORT using the da Vinci Xi surgical system (Sunnyvale, CA, USA).

\section{Incision and working space formation}

The patient was transorally intubated with an electromyogram tube (Medtronic, Minneapolis, MN, USA), and the tube was fixed to the right angle of the mouth (Supplementary video clip 1). Intraoperative neuromonitoring is routinely performed in our procedure to identify the recurrent laryngeal nerve (RLN) and the external branch of the superior laryngeal nerve, in order to prevent nerve injury during the operation. The patient was positioned supine with slight extension of her neck. After draping, the patient's oral cavity was irrigated with a solution of chlorhexidine and povidone-iodine. A diluted epinephrine-saline solution $(1: 200,000)$ was injected into the lower lip down to the chin for hydro-dissection. Then, we made an inverted U-shaped midline incision at $2 \mathrm{~cm}$ above the frenulum labii inferioris, measuring $1 \mathrm{~cm}$ in length. Subcutaneous tissue of the chin was dissected through the midline incision with Mosquito and Kelly clamps. Next, we injected the epinephrine-saline solution into the subplatysmal space with a Veress needle (Medtronic) for hydro-dissection of the subplatysmal plane. Then, blunt dissection with an 8-mmtipped vascular surgical tunneler was performed to separate the platysma from the strap muscles. After flap formation, an 8-mm midline trocar was inserted and carbon dioxide insufflation was maintained at the maximal pressure of 5-7 mmHg. Subsequently, we made $0.5-\mathrm{cm}$ lateral incisions near both angles of the mouth, and a similar blunt dissection was performed through the incisions to insert the $8-\mathrm{mm}$ trocars. Next, an ultrasonic energy device (HARMONIC ACE+, Ethicon Endo-Surgery, Cincinnati, $\mathrm{OH}, \mathrm{USA}$ ) and a suctionirrigator electrocautery through the lateral ports were used to elevate the platysma for working space creation from the level of the mandible to the sternum vertically and to both the sternocleidomastoid muscles horizontally. An additional 8-mm trocar was inserted through a right axillary incision for counter- traction of the strap muscles or perineural tissue, and for later insertion of the closed suction drain.

\section{Docking of robot}

After the creation of the working space, a da Vinci Xi Surgical System was docked laterally from the left with the patient laid in the supine position. Then, the robotic arms were docked to the ports, and the robotic instruments were inserted; A Maryland bipolar forceps to the left port, the harmonic scalpel to the right port, and 8-mm Prograsp bipolar forceps or a Maryland bipolar forceps to the right axillary port.

\section{Operative procedure}

First, the midline raphe was dissected using a monopolar hook cautery, and the isthmus was divided in the midline with an ultrasonic energy device. After detaching the isthmus from the trachea, the strap muscles were dissected from the thyroid gland (Fig. 1). Then, the superior pole was addressed. The sternothyroid muscle was retracted laterally with the Maryland bipolar forceps through the left intraoral port, and the thyroid gland was lifted up with the Maryland bipolar forceps through the axillary port. Then, careful dissection of the superior lobe was performed ligating one vessel at a time using an ultrasonic energy device or metal clips. Subsequently, the superior parathyroid gland was identified and dissected, and the ligament of Berry was dissected to identify the RLN with the ultrasonic energy device through the left intraoral port and Maryland bipolar forceps through the right intraoral port. The dissection was then performed inferiorly while tracing the RLN and preserving the lower parathyroid gland. Then, a prophylactic ipsilateral central compartment dissection was performed. The specimen was removed using an endoplastic bag through the axillary port, and a Jackson-Pratt drain was inserted.

\section{Operative outcomes}

The total operative time and the console time was 195 minutes and 110 minutes, respectively. There were no postoperative complications, and the patient was discharged on
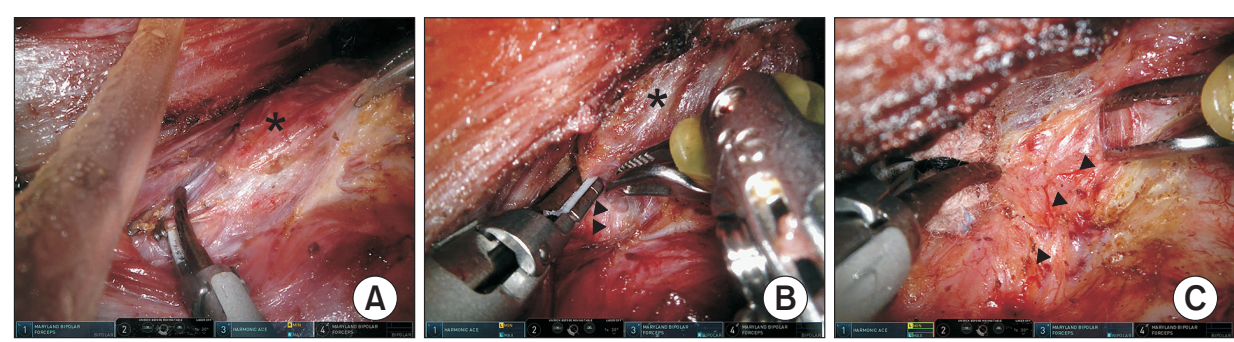

Fig. 1. The operative procedures of transoral robotic thyroidectomy. (A) Ligation of the superior thyroidal vessels of the left thyroid gland. (B) Identification of the left recurrent laryngeal nerve (arrowheads). (C) Completion of left thyroidectomy preserving recurrent laryngeal nerve (arrowheads). *Thyroid gland. 
postoperative day 2 after removal of the Jackson-Pratt drain. The final pathology demonstrated papillary carcinoma $0.9 \mathrm{~cm}$ in size, and metastasis in 1 out of 9 regional lymph nodes, with a final staging of pTlaNlaM0 (American Joint Committee on Cancer 8th edition).

\section{DISCUSSION}

Three hundred cases of TORT have been completed so far, and all cases were successfully performed without requiring open or endoscopic conversion [4-6]. Indications for TORT in our institute included (1) benign thyroid nodules of size less than $6 \mathrm{~cm}$, (2) nodules of size less than $4 \mathrm{~cm}$ that were suspicious of malignancy or being malignant (Bethesda category V or VI) in fine needle aspiration biopsy, and without extrathyroidal extension or extensive lymph node metastasis. Exclusion criteria included lateral neck lymph node metastasis, history of neck surgery, and history of radiation at the neck.

As mentioned earlier, left thyroid lobectomy by a transoral robotic approach is complicated when compared to right thyroid lobectomy. Since distance from the ports to the working space is close in TORT, performing the main procedure with righthanded instruments over the thyroid cartilage is difficult in left thyroid lobectomy by the transoral robotic approach. Such difficulty likely becomes even more prominent, especially during the superior pole dissection or in cases of male patients. However, as we demonstrated in this video clip, usage of the multiarticulation of the robotic instruments can make the procedure easier even for beginners. Transoral robotic left thyroidectomy and central neck dissection, therefore, could be safely performed for papillary thyroid carcinoma patients.

\section{CONFLICTS OF INTEREST}

No potential conflict of interest relevant to this article was reported.

\section{ACKNOWLEDGEMENTS}

This research was supported by a grant of the Korea Health Technology R\&D Project through the Korea Health Industry Development Institute (KHIDI), funded by the Ministry of Health and Welfare, Republic of Korea (HI14C3477).

\section{SUPPLEMENTARY MATERIAL}

Supplementary video clip 1 can be found via https://www. astr.or.kr/src/sm/astr-96-266-001.pdf.

\section{REFERENCES}

1. Anuwong A. Transoral endoscopic thyroidectomy vestibular approach: a series of the first 60 human cases. World J Surg 2016:40:491-7.

2. Chai YJ, Chung JK, Anuwong A, Dionigi G, Kim HY, Hwang KT, et al. Transoral endoscopic thyroidectomy for papillary thyroid microcarcinoma: initial experience of a single surgeon. Ann Surg Treat Res 2017:93:70-5.

3. Russell JO, Clark J, Noureldine SI, Anu- wong A, Al Khadem MG, Yub Kim H, et al. Transoral thyroidectomy and parathyroidectomy - A North American series of robotic and endoscopic transoral approaches to the central neck. Oral Oncol 2017;71:75-80.

4. Kim HY, Chai YJ, Dionigi G, Anuwong A, Richmon JD. Transoral robotic thyroidectomy: lessons learned from an initial consecutive series of 24 patients. Surg Endosc 2018;32:688-94.
5. Chai YJ, Kim HY, Kim HK, Jun SH, Dionigi G, Anuwong A, et al. Comparative analysis of 2 robotic thyroidectomy procedures: transoral versus bilateral axillo-breast approach. Head Neck 2018;40:886-92.

6. Kim HK, Kim HY, Chai YJ, Dionigi G, Berber E, Tufano RP. Transoral robotic thyroidectomy: comparison of surgical outcomes between the da Vinci Xi and Si. Surg Laparosc Endosc Percutan Tech 2018; 28:404-9. 